\title{
Geogratia
}

Malaysian Tournal of Society and Space

\section{Dilema majikan dalam isu menggaji pekerja tempatan atau pekerja asing di Malaysia: Perspektif majikan}

\author{
Nurina Awanis Mohamed, Mohd Na'eim Ajis, Zawiyah Md. Zain \\ Pusat Pengajian Kerajaan, Kolej Undang-Undang, Kerajaan dan Pengajian Antarabangsa, \\ Universiti Utara Malaysia
}

Correspondence: Nurina Awanis Mohamed (email: mnurinawanis@live.com.my)

Received: 14 April 2019; Accepted: 18 July 2019; Published: 22 August 2019

\begin{abstract}
Abstrak
Sikap majikan yang cenderung menggaji pekerja asing menimbulkan perdebatan dalam kalangan masyarakat. Terdapat sesetengah pihak mendakwa bahawa majikan tidak sepatutnya menggaji pekerja asing kerana pekerjaan yang ditawarkan mampu dikerjakan rakyat tempatan. Manakala, sesetengah pihak pula mendakwa bahawa majikan perlu menggaji pekerja asing disebabkan oleh faktor keengganan rakyat tempatan untuk terlibat dalam sektor pekerjaan 3D (Dirty, Dangerous, Difficult). Oleh demikian, artikel ini dijalankan bertujuan bagi meneroka permasalahan yang wujud dalam kalangan majikan mengenai isu menggaji pekerja. Selain itu, kajian turut meneliti tentang faktor kecenderungan penggajian pekerja asing berbanding pekerja tempatan dalam kalangan majikan. Bagi mencapai objektif kajian ini, kaedah kualitatif berbentuk temu bual secara mendalam digunakan melibatkan 10 orang pegawai yang terlibat dalam menguruskan penggajian pekerja asing. Hasil temu bual mendapati bahawa komitmen yang tinggi, kadar upah yang berpatutan, sikap tidak memilih pekerjaan dan taraf pendidikan yang rendah dalam kalangan pekerja asing menjadi faktor utama pihak majikan gemar menggaji pekerja asing berbanding pekerja tempatan. Kesimpulannya, pekerja asing diperlukan bagi membantu merancakkan ekonomi negara, namun penggajian pekerja asing yang tidak terkawal boleh memberi impak negatif bukan sahaja terhadap masyarakat malah mengancam keselamatan negara.
\end{abstract}

Kata kunci: faktor kecenderungan, majikan, pekerja asing, pekerja tempatan, permasalahan, sektor pekerjaan 3D 


\title{
Employer's dilemma on the issues of hiring foreign workers or local workers in Malaysia: Employer's perspective
}

\begin{abstract}
The attitudes of employers who tend to hire foreign workers cause debate among the public. Some claim that employers should not hire foreign workers because the jobs offered can be done by locals. On the other hand, some claim that employers need to hire foreign workers because of the reluctance of local people to engage in the 3D sector (Dirty, Dangerous, Difficult). Therefore, this article is intended to explore the issues that arise among employers regarding the issue of hiring. In addition, the study also examined the factors of the tendency to employ foreign workers compared to local workers among employers. To achieve the objective of this study, indepth qualitative interviewing method was used involving 10 officers involved in managing the employment of foreign workers. The results of the interviews showed that high commitment, reasonable wage rates, not choosing a job, and low educational attainment among foreign workers were a major factor for employers favoring foreign workers compared to local workers. In conclusion, foreign workers are needed to help boost the country's economy, but the employment of uncontrolled foreign workers can negatively impact not only on society but also on national security.
\end{abstract}

Keywords: factors of the tendency, employers, foreign workers, locals workers, issues, 3D sector

\section{Pengenalan}

Fenomena penggajian pekerja asing berlaku disebabkan oleh faktor kestabilan ekonomi yang dialami oleh sesebuah negara. Fenomena penggajian pekerja asing dapat dilihat di kebanyakan negara maju seperti di negara Eropah, Amerika Syarikat, Jepun, China dan Singapura. Keadaan ini dapat digambarkan melalui revolusi industri yang tercetus di negara Eropah yang menyebabkan perubahan terhadap struktur ekonomi (Hobsbawm, 1962) dan perubahan terhadap corak guna tenaga kerja di Eropah. Buktinya, pada tahun 1820 sehingga 1840, kebanyakan pengusaha kilang di New England menggunakan tenaga kerja tempatan yang terdiri daripada golongan wanita dan kanak-kanak (Goldin \& Sokoloff, 1982). Namun, pada tahun 1860 sehingga 1920, pengusaha kilang terpaksa menggaji pekerja dari Ireland, Scotland dan Wales walaupun mereka tidak mempunyai kemahiran (Spielvogel, 2012).

Fenomena ini turut dialami di kebanyakan negara membangun termasuklah Malaysia. Kadar pertumbuhan Keluaran Dalam Negara Kasar (KDNK) sebanyak 8.9 peratus pada tahun 1991 sehingga 1995 (Zulkifly, 1998) telah memberikan impak positif terhadap peningkatan taraf hidup masyarakat dan sekaligus mengubah persepsi dan minat rakyat tempatan terhadap sektor pekerjaan (MPI, 2018). Keadaan ini menyebabkan sektor pekerjaan 3D kurang mendapat sambutan dalam kalangan masyarakat tempatan dan mewujudkan kelompangan tenaga kerja yang besar. Buktinya, sektor perladangan getah dan kelapa sawit mengalami kerugian sebanyak RM370 juta pada tahun 1980 sehingga 1985 (Zulkifly, 1998). Oleh demikian, pihak kerajaan terpaksa menggaji pekerja asing bagi memenuhi permintaan industri (Azizah, 2012). 
Kebenaran yang diberikan oleh pihak kerajaan telah disalahgunakan oleh pihak majikan kerana sebahagian daripada mereka cenderung menggaji pekerja asing berbanding pekerja tempatan (Azizah, 2014; Edwin \& Kamal, 2015). Namun, dakwaan ini disangkal oleh Presiden Persekutuan Majikan-Majikan Malaysia (MEF) dan menegaskan bahawa pihak majikan mempunyai justifikasi yang kukuh dalam isu menggaji pekerja asing (Shamsuddin, 2002). Oleh demikian, artikel ini dilakukan bertujuan bagi meneroka permasalahan yang wujud dalam kalangan majikan mengenai isu penggajian pekerja sama ada pekerja tempatan atau pekerja asing. Selain itu, artikel ini dilakukan bertujuan bagi mengenal pasti justifikasi pihak majikan terhadap isu penggajian pekerja asing berbanding pekerja tempatan. Bagi mencapai objektif kajian, pengkaji menjalankan temu bual seramai sepuluh orang informan mewakili pelbagai kementerian dan agensi yang terlibat dalam menguruskan penggajian pekerja asing di Malaysia.

\section{Kajian literatur}

Kajian yang membahaskan tentang penggajian pekerja asing sudah banyak oleh pengkaji terdahulu sama ada dalam dan luar negara yang meliputi pelbagai bidang, antaranya seperti ekonomi, sosial, politik, perundangan, perubatan, sejarah, demografi dan geografi. Kebanyakan kajian-kajian lepas memfokuskan aspek kesan penggajian pekerja asing di sesebuah negara, antaranya seperti di Britain (Kangasniemi et al., 2008); Amerika Syarikat (Peri, 2012; Clemens, 2013), Singapura (Ramesh, Charles \& Peter, 2012; Yap Mui Teng, 1999), Jepun (Nakamura, 2010) dan Malaysia (Hamzah et al., 2012; Rahmah \& Ferayuliani, 2014; Siti Rohayu et al., 2014; Nur Sabrina et al., 2014; Hazrul \& Zulkifli, 2017). Walaupun sudah banyak kajian telah dijalankan yang menyentuh mengenai aspek kesan penggajian pekerja asing namun masih wujud beberapa kelemahan dalam kajian berkenaan, antaranya seperti kurang memberi perhatian terhadap faktor penggajian pekerja asing di sesebuah negara. Oleh demikian, kajian ini dijalankan bertujuan bagi mengenal pasti faktor yang mempengaruhi penggajian pekerja asing di negara Malaysia.

Kajian yang membincangkan faktor pengambilan pekerja asing dari sudut negara telah dilakukan oleh pengkaji seperti Azizah (2012) dan Mohd Na'eim (2015) yang meneliti tentang faktor ekonomi negara yang menjadi penyebab penggajian pekerja asing terpaksa dilakukan, contohnya, kestabilan ekonomi yang dialami dalam Rancangan Malaysia Keenam (RMK6) menjadi penyebab pengambilan pekerja asing di Malaysia. Keadaan yang sama turut berlaku di Singapura, iaitu perkembangan pesat industri yang berasaskan eksport pada akhir tahun 1960-an dan 1970-an telah menyebabkan permintaan kepada tenaga buruh meningkat (Yen \& Piper, 2009; Hui, 1997). Selain itu, dasar pendidikan yang berjaya dilaksanakan oleh pihak kerajaan telah mempengaruhi minda rakyat tempatan untuk terlibat ata bekerja dalam sektor pekerjaan yang dianggap murah (Mohd Na'eim et al, 2010).

Manakala kajian yang mengupas faktor pengambilan pekerja asing yang melihat dari sudut rakyat dilakukan oleh pengkaji seperti Sonthisakyothin (2000) yang berhujah bahawa sektor pekerjaan 3D kurang mendapat sambutan daripada rakyat tempatan menjadi faktor penggajian pekerja asing di Thailand. Manakala di Malaysia, penggajian pekerja asing terpaksa dilakukan disebabkan oleh faktor sikap rakyat tempatan itu sendiri (Abd. Kadir et al., 2017) dan faktor migrasi dalaman yang berlaku (Nor Ermawati et al., 2015; Mohd Fadzli et al., 2016). Selain itu, laporan yang dijalankan oleh pihak CIDB mendapati bahawa rakyat tempatan kurang berminat untuk melibatkan diri dalam sektor pembinaan disebabkan oleh lima faktor, iaitu amalan bayaran upah yang mengikut hari atau kuantiti, persekitaran kerja yang kurang selesa, risiko keselamatan 
di tapak binaan, kecenderungan kontraktor tempatan dan imej kerjaya yang tidak meyakinkan (CIDB, 2004).

Namun, hanya segelitir sahaja kajian yang membahaskan mengenai faktor penggajian pekerja asing menurut perspektif majikan. Faktor penggajian pekerja asing di sesebuah negara berlaku disebabkan oleh faktor desakan dari golongan majikan. Permintaan yang tinggi daripada pihak majikan menjadi faktor penggajian pekerja asing terpaksa dilakukan, terutamanya melibatkan sektor formal seperti sektor pertanian, perladangan, pembinaan, perkilangan. Penggajian pekerja asing di Semenanjung Malaysia kebanyakan tertumpu dalam sektor pembuatan, pembinaan (Zakaria, 2005), manakala penggajian pekerja asing di Sabah dan Sarawak tertumpu dalam sektor pertanian (Rahmah et al., 2017). Oleh demikian, kajian ini dijalankan bertujuan bagi meneliti faktor penggajian pekerja asing menurut perspektif majikan.

\section{Metod kajian}

Reka bentuk yang digunakan dalam kajian ialah bersifat kualitatif yang menggunakan data primer dan sekunder yang dikumpul melalui beberapa kaedah. Pengumpulan data primer dijalankan melalui kaedah temu bual bersama dengan pihak-pihak yang terlibat dalam menguruskan penggajian pekerja asing. Informan yang ditemu bual dalam kajian ini melibatkan 10 orang informan yang terdiri daripada pihak Kementerian Dalam Negeri (KDN), Kementerian Sumber Manusia (KSM), Kementerian Pertanian dan Industri Asas Tani (MOA), Kementerian Industri Utama (MPI), Lembaga Pembangunan Industri Pembinaan Malaysia (CIDB), Kongres Kesatuan Sekerja Malaysia (MTUC), Persekutuan Majikan Malaysia (MEF), Pertubuhan Kebangsaan Agensi Pekerjaan Malaysia (PIKAP), Persatuan Kontraktor Melayu Malaysia (PKMM) dan Kedutaan Indonesia.

Manakala, data sekunder dikumpul dan diperoleh melalui dua kaedah, iaitu sumber secara bercetak atau tidak bercetak yang diterbitkan atau tidak diterbitkan, antaranya seperti buku, dokumen sejarah, jurnal, keratan akhbar, laporan bertulis daripada pihak berkuasa, majalah dan dokumentasi perundangan. Kaedah temu bual secara semi-struktur merupakan instrumen utama yang digunakan dalam kajian ini. Hal ini kerana persoalan yang dikemukakan kepada informan boleh diubah suai sama ada dari segi susunan atau kaedah dalam menyoal agar lebih bersifat fleksibel. Semua data dan maklumat yang diperoleh, diproses dan dianalisis menggunakan laporan secara deskriptif dan analitikal.

\section{Hasil kajian dan perbincangan}

\section{Dilema dan justifikasi penggajian pekerja asing berbanding pekerja tempatan}

Terdapat empat dilema yang terpaksa dihadapi oleh pihak majikan dalam isu menggaji seseorang pekerja. Dilema yang pertama dihadapi oleh pihak majikan ialah berkaitan dengan isu komitmen. Komitmen bermaksud seseorang pekerja meletakkan keutamaan yang tinggi terhadap tugas atau kerja (Noralai \& Norhasni, 2010). Komitmen merupakan elemen penting yang dititikberatkan oleh majikan sebelum menggaji seseorang pekerja kerana elemen ini boleh mempengaruhi prestasi sesebuah syarikat atau perniagaan (KDN, 2016). Berdasarkan hasil temu bual yang dilakukan kebanyakan informan mengakui bahawa pekerja tempatan suka meminta cuti sakit 
(Kedutaan Indonesia, 2017), lewat datang kerja (KDN, 2016), tidak sanggup bekerja lebih masa (KDN, 2016; MEF, 2016), tidak mahu tinggal di kuarters yang telah disediakan oleh pihak majikan (MOA, 2013), tidak suka diganggu ketika cuti hujung minggu dan lebih mengutamakan komitmen sosial berbanding komitmen kerja, buktinya, setiap minggu akan mereka akan pulang ke kampung (PIKAP, 2017). Keadaan ini memberi gambaran yang jelas tentang dilema yang terpaksa dihadapi oleh pihak majikan.

Selain daripada dilema tersebut, pihak majikan turut menghadapi dilema dalam sektor tertentu yang memerlukan tenaga kerja manual secara konsisten, contohnya, aktiviti penuaian buah kelapa sawit, penanaman bunga, penternakan haiwan atau unggas memerlukan komitmen yang tinggi dan perlu dilakukan mengikut jadual yang telah ditetapkan. Jika pekerja tersebut tidak menepati masa yang ditetapkan atau tidak datang bekerja, hasil tanaman akan rosak dan ternakan akan mati (MOA, 2013). Keadaan ini diakui oleh wakil daripada pihak MPI (2017) dengan berkata:

“...Sektor perladangan antara sektor 3D. Sektor ini memerlukan tenaga buruh secara manual. Kementerian belia cuba menarik minat golongan belia untuk bekerja di sektor perladangan namun, gagal. Bagi jawatan Kadet Planters ke atas (taraf eksekutif), kebanyakanya diisi oleh orang tempatan. Majikan bukan tak nak ambil pekerja tempatan. Kalau ikut pengalaman saya, setiap pagi akan ada sesi penerangan (roll call) antara 6.15 sehingga 6.30am). Mandur akan memberi penjelasan kepada pekerja (tempatan dan asing) tentang objektif dia pada hari tersebut. Biasanya, yang melaksanakan arahan ini kebanyakan dari pekerja asing. Hal ini kerana pekerja tempatan sering tidak datang bekerja atau tidak konsisten. Senario ini berlaku di ladang seperti Gua Musang dan Pahang. Jadi, syarikat bergantung kepada hasil tuaian kelapa sawit”.

Kenyataan yang dikemukakan oleh wakil daripada pihak MPI ini turut disokong oleh wakil daripada pihak MEF (2016) dengan berkata:

"...Sebagai majikan, mereka mahukan liabiliti, zero absentisme dan willingness to work. Sikap pekerja tempatan kita tidak begitu memberangsangkan. Kalau kita ambil bekerja, mungkin tahan 2, 3 minggu kemudian dia lari. Majikan prefer to have consistency of manpower. Kalau kita ambil 100, 23 orang akan lari. Oleh sebab itu, majikan lebih prefer untuk menggajikan pekerja asing kerana sikap mereka mahu bekerja. Pekerja kita ini, apabila keadaan masyarakat lebih maju mereka lebih memikirkan perkara-perkara lain, contoh, nak buat overtime dia tak nak sebab ada kenduri. Dengan hal yang demikian, majikan terpaksa ambil pekerja asing disebabkan sikap pekerja tempatan yang berkelakuan sedemikian”.

Tahap komitmen yang rendah dan prestasi yang kurang memuaskan menjadi punca pihak majikan tidak mahu menggaji pekerja tempatan dalam sektor pekerjaan 3D. Dilema yang dihadapi oleh pihak majikan ini menyebabkan mereka mula beralih arah dari guna tenaga kerja tempatan kepada guna tenaga kerja asing. Peralihan ini dilihat sebagai tindakan yang wajar dilakukan oleh pihak majikan kerana sikap dan komitmen tinggi yang dimiliki oleh pekerja asing menjadi faktor penarik kepada pihak majikan untuk mengambil pekerja asing bekerja. Menurut Shamsuddin (2002), sesetengah majikan beranggapan bahawa pekerja asing lebih bersikap 
positif dan tidak banyak karenah dalam melakukan kerja dan boleh bekerja lebih masa. Keadaan ini diakui oleh wakil responden dari pihak PKMM (2016) dengan berkata:

“...Pasal mereka komited. Pertama boleh arah dan boleh marah. Kedua, kalau you tak bayar pun tak apa. Kebanyakan majikan tak bayar tau dan ada yang abuse sebab tak legal. Tapi, dia boleh tolak ansur dan tak kenal kan, sebab dia Indonesia kan. Kalau tempatan, esok jumpa lagi. Alamak, sedara-mara, jumpa tak bayar. Kalau Indonesia tak suka cakap, kalau local suka bercerita kat sapa-sapa. Culture, commitment, attitude tu lain. Pendatang lain, pemastautin lain".

Perbezaan yang amat ketara dari segi komitmen yang ditunjukkan antara pekerja tempatan dengan pekerja asing menggambarkan realiti sebenar mengapa kebanyakan majikan gemar menggaji pekerja asing berbanding pekerja tempatan. Mereka bukan sahaja rajin, taat, malah sanggup bekerja lebih masa dan tidak pernah meminta cuti (Narayanan \& Lai, 2007; Narayanan \& Lai, 2014; KDN, 2016; KSM, 2016). Perbezaan yang wujud antara pekerja asing dengan pekerja tempatan ini turut diakui oleh Azizah (2014) dengan berkata:

“...Majikan suka kepada pekerja asing sebab mereka tidak mempunyai komitmen seperti pekerja tempatan yang mempunyai pelbagai komitmen. Pekerja asing dianggap tidak mempunyai obligasi sosial dan mereka suka kalau diberi overtime. Mereka datang untuk mencari nafkah semata-mata. Orang kita different standard of living berbanding mereka yang datang tu. Macam saya buat kajian terhadap orang Nepal, mereka cakap kalau duduk di rumah pun nak buat apa baik pergi kerja sebab anak bini pun ada kat kampung".

Dilema yang kedua dihadapi oleh pihak majikan dalam menggaji seseorang pekerja ialah berkaitan dengan isu gaji. Rakyat tempatan beranggapan bahawa sektor pekerjaan 3D merupakan sektor yang menawarkan gaji rendah dan tidak setimpal dengan hasil kerja yang dilakukan. Persepsi sedemikian perlu diubah kerana tidak semua sektor pekerjaan 3D menawarkan gaji yang rendah. Buktinya, sektor pembinaan terutamanya operasi kren menawarkan kadar upah yang tinggi, iaitu antara RM24 hingga RM25 sejam atau RM3,500 hingga RM4,000 sebulan dan kadar upah ini tidak termasuk kerja lebih masa (Rashiqah \& Azila, 2018). Manakala, kerja-kerja di tapak pembinaan pula menawarkan gaji antara RM2,000 hingga RM3,00 sebulan (CIDB, 2017). Selain itu, bidang kimpalan dalam sektor pembinaan menawarkan gaji sebanyak RM3,000 hingga RM6,000 sebulan dan bergantung kepada projek dan kemahiran masing-masing (Roskhoirah, 2015). Kenyataan ini turut disokong oleh wakil dari pihak MPI (2017) dengan berkata:

“...Soal gaji bagi penuai RM3,000 hingga RM4,000 per month. Sebab itulah orang Indonesia sanggup untuk datang bekerja. Senario ini berubah selepas Jokowi mengambil alih pentadbiran. Jokowi menggesa warga Indonesia supaya bekerja di Indonesia berbanding di Malaysia. Jadi, mereka tidak lama menetap dan bekerja di Malaysia".

Penjelasan ini membuktikan bahawa kebanyakan sektor pekerjaan 3D yang ditawarkan menjanjikan pendapatan yang lumayan. Namun, jika persepsi masyarakat terhadap sektor 
pekerjaan 3D ini tidak diubah, hal ini boleh menimbulkan kesukaran kepada pihak majikan untuk mendapatkan pekerja tempatan. Kesannya, pihak majikan terpaksa menggaji pekerja asing untuk mengisi kekosongan yang ada. Tambahan pula, kebanyakan pekerja asing tidak mementingkan aspek gaji malah ada dalam kalangan mereka sanggup bekerja lebih masa dan menerima kadar upah yang lebih rendah berbanding dengan kadar upah yang diperoleh pekerja tempatan (Siti Rohayu et al., 2014; Rahmah et al., 2017). Oleh demikian, keadaan ini menjadi faktor yang mendorong pihak majikan untuk memilih dan menggaji pekerja asing berbanding pekerja tempatan.

Dilema yang ketiga dihadapi oleh pihak majikan dalam menggaji seseorang pekerja ialah berkaitan dengan sikap. Hasil temu bual yang dijalankan bersama dengan informan kebanyakan bersetuju bahawa kebanyakan rakyat tempatan gemar memilih kerja, tidak kekal dalam tempoh yang lama dan sering bertukar-tukar pekerjaan (Mohd Na'eim, 2015). Kenyataan ini diakui oleh informan daripada pihak Kedutaan Indonesia (2017) dengan berkata:

“...Berdasarkan kepada informasi daripada para majikan, penyebab utama mereka mengambil pekerja asing adalah disebabkan, sulitnya mendapatkan pekerja tempatan untuk jawatan-jawatan yang ditawarkan khususnya dalam sektor pekerjaan 3D, selain faktor pekerja tempatan juga tidak boleh bekerja secara kekal, sikap mereka yang sering $M C$, mudah keluar masuk kerja bertukar majikan sesuka hati”.

Sikap memilih kerja dalam kalangan pekerja tempatan juga dipengaruhi oleh faktor status sosial. Kebanyakan rakyat tempatan lebih mementingkan status sosial dalam sesebuah masyarakat. Oleh demikian, tindakan memilih pekerjaan dalam kalangan rakyat tempatan dilihat sebagai tindakan yang wajar dilakukan selaras dengan teori hierarki Maslow (Maslow, 1943), contohnya, sektor pekerjaan yang dikategorikan 3D dianggap sebagai sektor pekerjaan yang berstatus rendah dalam hierarki sosial. Hal ini diakui oleh Mohd Na'eim (2015) yang berpendapat bahawa kebanyakan rakyat tempatan tidak mahu terlibat dalam sektor pekerjaan 3D kerana keadaan persekitaran yang kotor, panas dan mencabar.

Tambahan pula, menurut Zakaria (2005), terdapat sesetengah pekerja tempatan sanggup bekerja dalam sektor lain yang menawarkan upah yang lebih rendah asalkan memperolehi pekerjaan dan pendapatan terjamin atau tetap. Sikap yang wujud dalam kalangan rakyat tempatan ini boleh mengundang dilema kepada pihak majikan untuk menggaji pekerja tempatan dan menyebabkan majikan terpaksa memilih untuk menggaji pekerja asing bagi mengisi kekosongan yang ditinggalkan oleh pekerja tempatan, terutamanya dalam sektor pekerjaan 3D. Keadaan ini dapat dilihat dalam sektor perladangan yang memerlukan tenaga buruh secara manual. Namun, ketiadaan tenaga kerja tempatan untuk membanting tulang menyebabkan pihak majikan terpaksa mengambil tenaga kerja asing. Hal ini diakui oleh wakil daripada pihak MPI (2017) dengan berkata:

“...Dilema sekarang yang dialami ialah dari segi penuai (main player). Jika keperluan guna tenaga kurang, hal ini boleh menjejaskan produktiviti industri kelapa sawit. Wujud satu gap yang tidak diisi oleh pekerja tempatan dan kini diisi oleh pekerja asing. Dahulu, sektor pekerjaan ini diisi oleh pekerja tempatan tetapi sekarang tidak". 
Fenomena ini bukan sahaja berlaku dalam sektor perladangan malah turut berlaku dalam sektor pembinaan. Hal ini diakui oleh wakil daripada pihak MPI (2013) dengan berkata:

“...Memang betul orang kita memilih kerja, mereka tak mahu kerja yang kotor dan susah. Pelatih-pelatih Akademi Binaan Negara (ABN) yang kita keluarkan tak mahu menyertai sektor pembinaan selepas tamat latihan dan ada di antara mereka yang buka kedai makan dan bekerja kilang. Kita sebenarnya tidak mempunyai kuasa atau peraturan yang boleh memaksa mereka bekerja di sektor pembinaan”.

Dilema keempat yang dihadapi oleh pihak majikan untuk menggaji seseorang pekerja ialah berkaitan dengan isu taraf pendidikan. Pertumbuhan KDNK yang tinggi direkodkan dalam RMK6 telah memberikan kesan positif terhadap taraf hidup rakyat Malaysia, terutamanya dari segi pendidikan. Peluang untuk melanjutkan pelajaran kian terbuka luas sekali gus mengubah minat dan aspirasi golongan berpendidikan terhadap pekerjaan (KDN 2016; Azizah, 2012). Oleh demikian, masyarakat meletakkan persepsi bahawa pendidikan yang tinggi boleh dijadikan sebagai pasport untuk mendapatkan peluang pekerjaan yang lebih baik dengan pendapatan yang lebih lumayan (MPI, 2018). Persepsi ini bukan sahaja wujud dalam kalangan golongan berpendidikan malah melangkaui minda rakyat tempatan secara keseluruhannya.

Keadaan ini mewujudkan dilema kepada pihak majikan kerana kebanyakan rakyat tempatan mempunyai taraf pendidikan yang tinggi. Hal ini secara tidak langsung menyebabkan sektor pekerjaan 3D seperti pertanian, perladangan, perkilangan, pembinaan dan perkhidmatan termasuk sektor pembantu rumah mengalami masalah kekurangan tenaga kerja tempatan. Hal ini diakui oleh pihak majikan dan menyatakan bahawa kebanyakan golongan muda yang mempunyai kelulusan tinggi tidak mahu terlibat dalam sektor pekerjaan 3D yang dikategorikan sebagai pekerjaan yang tidak setaraf dengan kelayakan yang dimiliki oleh mereka (Mohd Na'eim et al., 2014; MPI, 2017; KSM, 2018). Keadaan ini sudah tentu akan mewujudkan kelompangan yang besar dalam guna tenaga kerja dalam sektor tertentu. Oleh demikian, pihak majikan tidak mempunyai pilihan lain dan terpaksa mengaji pekerja asing bagi memastikan kelangsungan produktiviti ekonomi industri dan perniagaan mereka.

Fenomena yang melanda negara ini turut diakui oleh Azizah (2014) dan berpendapat bahawa sistem pendidikan negara telah menukar minat dan aspirasi golongan berpelajaran terhadap bidang pekerjaan. Buktinya, golongan belia tidak berminat untuk terlibat dalam sektor pekerjaan 3D dan lebih memilih untuk terlibat dalam sektor pekerjaan formal sama ada dalam sektor awam atau swasta. Malah, taraf pendidikan yang semakin meningkat dalam kalangan wanita juga telah membuka ruang terhadap kemasukan pekerja asing. Kedua-dua situasi ini jelas menunjukkan bahawa sistem pendidikan sesebuah negara telah mempengaruhi trend dan corak guna tenaga kerja dalam sektor pekerjaan 3D. Bagi mengatasi isu ini, pihak MEF mencadangkan kepada pihak kerajaan agar memperkenalkan semula program latihan, pendidikan vokasional dan teknikal (TVET) dalam sistem pendidikan. Hal ini dilakukan bertujuan bagi melahirkan tenaga kerja yang profesional seperti yang dikemukakan oleh informan daripada pihak MEF (2013) seperti berikut:

“...By Technical, Vocational Education and Training (TVET), we are able to actually introduce the kind of the technical savvy employees, vocational employees that is actually being required by the market. In term of perception, we have a big problem where most parents are not interested in that. And the student also are really not 
interested because they are considered as a second or third class education system. But this is different in other country like Singapore whereas TVET is being mainstreamed and the technician produced is granted by Harvard University. Therefore, the negative perception towards TVET must be eliminated because we want to produce technical and vocational people in order they can fill in the vacancies in the industries".

\section{Kesimpulan}

Berdasarkan kepada perbincangan yang dilakukan bersama dengan informan yang mewakili pelbagai kementerian dan agensi, dapat disimpulkan bahawa faktor kecenderungan pihak majikan terhadap isu penggajian pekerja asing adalah bersandarkan kepada empat dilema yang terpaksa dihadapi oleh pihak majikan untuk menggaji seseorang pekerja. Empat dilema tersebut merangkumi isu komitmen, gaji, sikap memilih pekerjaan dan taraf pendidikan.

Terdapat beberapa pihak tetap tidak bersetuju dengan tindakan yang dilakukan oleh pihak majikan kerana cenderung menggaji pekerja asing berbanding dengan pekerja tempatan dalam sektor pekerjaan 3D. Kecenderungan tersebut bukan bermaksud pihak majikan tidak berusaha mencari pekerja tempatan malah kebanyakan daripada majikan mengakui bahawa mereka mahu menggaji pekerja tempatan berbanding pekerja asing. Namun, pihak majikan tidak mempunyai pilihan lain dan mempunyai justifikasi yang kukuh dalam isu menggaji pekerja asing meskipun terpaksa menjalani pelbagai prosedur yang rumit dan menanggung kos yang tinggi.

Kesannya, penggajian pekerja asing ini bukan sahaja mengundang isu negatif kepada masyarakat seperti isu budaya, isu perumahan setinggan, isu jenayah, isu keselamatan penduduk setempat malah boleh mengancam keselamatan dan kedaulatan negara dengan wujudnya kelompok pendatang asing tanpa izin (PATI). Selain itu, dakwaan yang mengatakan bahawa majikan hanya cenderung menggajikan pekerja asing merupakan dakwaan yang tidak tidak benar sama sekali kerana majikan terpaksa melalui proses yang telah ditetapkan oleh KDN dan KSM. Buktinya, pihak KSM mewajibkan setiap majikan untuk mengiklankan kekosongan jawatan di laman sesawang, iaitu di Job Malaysia. Setelah kekosongan jawatan tersebut diiklankan dan tiada pekerja tempatan untuk mengisi kekosongan tersebut barulah majikan boleh menggajikan pekerja asing.

Walaupun penggajian pekerja asing dilakukan bertujuan bagi memenuhi sektor pekerjaan 3D yang dikatakan kurang digemari oleh rakyat tempatan, terutamanya golongan belia, namun penggajian pekerja asing perlu dilakukan secara terkawal, sistematik dan mengikut kuota yang telah ditetapkan oleh kerajaan bagi mengelakkan kebergantungan terhadap pekerja asing. Jika penetapan dari segi undang-undang tidak dipatuhi sepenuhnya oleh pihak majikan, keadaan ini boleh mengundang implikasi negatif bukan sahaja terhadap masyarakat malah memberi ancaman buruk kepada negara. 


\section{Rujukan}

Abd. Kadir Batong, Rostika Petrus Boroh, \& Beatrice Lim. (2017). Faktor yang mempengaruhi belia untuk tidak bekerja: Kajian kes di daerah Tawau, Sabah. Proceedings of International Conference on Economics 2017 (ICE 2017). 493-500.

Azizah Kassim. (2012). Dasar pekerja asing di Malaysia: Perlunya anjakan paradigma. Bangi, Universiti Kebangsaan Malaysia.

Azizah Kassim. (2014). Recent trends in transnational population inflows into Malaysia: Policy, issues and challenges. Malaysian Journal of Economic Studies, 51(1), 9-28.

Azizah Kassim. (2014, Januari 13). Personal Interview.

CIDB Malaysia. (2004), Tinjauan Industri Binaan 2001-2002. Kuala Lumpur, Lembaga Pembangunan Industri Pembinaan Malaysia (CIDB).

Clemens, M. (2013). The effect of foreign labor on native employement: A job-specific approach and application to North Carolina Farms (Working Paper No. 326).

Edwin Ong Ewe Lim, \& Kamal Halili Hassan. (2015). Perlindungan hak asas pekerja asing. In Kamal Halili Hassan (Ed.). Buruh asing dan migrasi: Isu perundangan. Bangi, Universiti Kebangsaan Malaysia.

Goldin, C., \& Sokoloff, K. (1982). Women, children, and industrialization in the early republic: Evidence from the manufacturing censuses. The Journal of Economic History, XLII(4), 741774.

Hamzah Abdul-Rahman, Chen Wang, Lincoln C.W., \& Shu Fung Lowa. (2012). Negative impact induced by foreign workers: Evidence in Malaysian construction sector. Habitat International, 36, 433-443.

Hazrul Shahiri \& Zulkifli Osman. (2017). Pulangan monetari pekerja terancam di Malaysia berdasarkan kepada teori upah Hedonik. Jurnal Ekonomi Malaysia, 51(1), 69-78.

Hobsbawm, E. (1962). The age of revolution, 1789-1900. London, Weidenfeld \& Nicolson.

Hui, W.T. (1997). Regionalisation, economic restructuring and labour migration in Singapore. International migration, 35(1), 110-130.

Kangasniemi, M., Mas, M., Robinson, C., \& Serrano, L. (2008). The economic impact of migration: Productivity analysis for Spain and the UK. EU KLEMS Conference, Brussels. National Institute of Economic and Social Research, UK and University of Valencia, Spain.

Kedutaan Indonesia. (2017, Februari 22). Personal Interview.

Kementerian Dalam Negeri (KDN). (2016, Oktober 17). Personal Interview.

Kementerian Industri Utama Malaysia (MPI). (2017, Mac 17). Personal Interview.

Kementerian Industri Utama Malaysia (MPI). (2018, 22 Mac). Personal Interview.

Kementerian Pertanian dan Industri Asas Tani (MOA). (2013, November 19). Personal Interview.

Kementerian Sumber Manusia (KSM). (2016, Oktober 9). Personal Interview.

Malaysian Employer Federation (MEF). (2016, November 16). Personal Interview.

Maslow, A.H. (1943). A theory of human motivation. Psychological Review, 50, 370-396.

Mohamad Fauzi Sukimi, \& Muhd Ridhwan Sarifin. (2014). Negara, undang-undang dan tenaga kerja asing: Antara ideal dan realiti di Malaysia. Geografia-Malaysian Journal of Society and Space, 10(1), 101-109.

Mohd Fadzli Abdul Rashid, Suharto Teriman, Wan Rabiah Wan Omar \& Mohd Roswodi Mohd Zin. (2016). Migrasi bandar-bandar di Malaysia: Kajian kes wilayah koridor ekonomi pantai timur. Geografia-Malaysian Journal of Society and Space, 12(4), 131-146. 
Mohd Na'eim Ajis, Hishamuddin Md. Som, Mohamad Nasir Saludin, Azman Ismail, Md. Shukri

Mohd Na'eim Ajis. (2015). Pembuatan dan pentadbiran dasar pekerja asing di Malaysia. (Phd dissertation). Universiti Sains Malaysia, Pulau Pinang, Malaysia.

Nakamura, Jiro. (2010). Impacts of international migration on the labor market in Japan. Japan Labor Review, 7(3), 68-85.

Narayanan, S., \& Lai, Y.W. (2007). Strategies to reduce the dependence of the Malaysian economy on immigrant labour. Report for the National Economic Action Council (MTEN), Government of Malaysia, Kuala Lumpur.

Narayanan, S., \& Lai, Y.W. (2014). Migration and development in Malaysia: The impact of immigrant labour on the manufacturing sector, 1986-2010. National Population Conference on the Inter-Relationship between Population Dynamics and Development. Population Studies Unit of the University of Malaya in collaboration with the National Population and Family Development Board. Retrieved from http://familyrepository.lppkn.gov.my

Nor Ermawati Hussain, Norehan Abdullah \& Hussin Abdullah. (2015). Hubungan migrasi dalaman dengan faktor-faktor penarik: Kajian kes di Malaysia. Jurnal Ekonomi Malaysia, 49(2), 121-133.

Noralai Ismail \& Norhasni Zainal Abidin. (2010). Tinjauan faktor-faktor yang mempengaruhi komitmen pekerja terhadap organisasi. Dinamika Sosial Ekonomi, 6(1), 1-16.

Nur Sabrina Mohd Palel, Rahmah Ismail \& Abdul Hair Awang. (2014). Kesan kemasukan buruh asing ke atas produktiviti buruh sektor pembuatan di Malaysia. Prosiding PERKEM ke-9. 89-103.

Peri, G. (2012). The effect of immigration on productivity: Evidence from U.S. States. Review of Economics and Statistics, 94(1), 348-358.

Persatuan Kontraktor Melayu Malaysia (PKMM). (2016, 27 Disember). Personal Interview.

Pertubuhan Kebangsaan Agensi Pekerjaan Malaysia (PIKAP). (2017, 3 Mei). Personal Interview.

Rahmah Ismail \& Ferayuliani Yuliyusman. (2014). Foreign labour on Malaysian growth. Journal of Economic Integration, 29(4), 657-675.

Rahmah Ismail, Norsarah Yasmin Norzaki \& Mohd Nasir Mohd Saukani. (2017). Keanjalan buruh-output dan keperluan pekerja asing dalam sektor pembuatan di Malaysia. Jurnal Ekonomi Malaysia, 51(1), 3-14.

Ramesh Kumar Monna Mohamed, Charles Ramendran, S.P.R., \& Peter Yacob. (2012). International Journal of Academic Research in Business and Social Sciences, 2(10), 531541.

Ramli Dollah, \& Kamarulnizam Abdullah. (2017). Wacana hegemoni dan dasar pekerja asing di Malaysia: Kajian kes ke atas persaingan elit pemerintah dan towkays di Sabah. Jurnal Komunikasi Borneo, 5.

Ramli Dollah, \& Kamarulnizam Abdullah. (2019). Serbuan, pengusiran dan krisis tenaga kerja di Malaysia: Dilema negara dan dasar tenaga kerja asing di Sabah. Borneo Research Journal, 9, 19-44.

Rashiqah Ilmi Abd Rahim, \& Siti Azila Alias. (2018). Operasi kren dimonopoli warga asing. Retrieved from http://www.bhplus.com.my

Roskhoirah Yahya. (2018). Mampu raih RM6,000 sebulan: Kerja binaan gaji lumayan. Retrieved from http://www.kkr.gov.my

Shamsuddin Bardan. (2018). Majikan tiada pilihan guna pekerja asing. Retrieved from http://www.utusan.com.my 
Shuib, \& Mohamad Faisol Keling. (2010). Dasar dan pengurusan pekerja asing di negaranegara Asia Tenggara. INTAN Management Journal, 11(1), 41-75.

Siti Rohayu Norsi'ee, Rahmah Ismail \& Norlin Khalid. (2014). Impak pekerja asing terhadap upah firma perusahaan kecil sederhana sektor pembuatan di Malaysia. Prosiding PERKEM ke-9.104-116.

Sonthisakyothin Sakdian. (2000). Major factor affecting policy charges on illegal migrant workers in Thailand. Thailand, The National Institute of Development Administration.

Spielvogel, J.J. (2012). Western civilization: Advantage edition. $\left(8^{\text {th }}\right.$ ed.). USA, Wadsworth Cengage Learning.

Yap Mui Teng. (1999). The Singapore state's response to migration. Sojourn: Journal of Social Issues in Southeast Asia, 14(1), 198-211. Retrieved from http://www.jstor.org

Yen, T.Y., \& Piper, N. (2009). Foreigners in our homes: Linking migration and family policies in Singapore. Population Space and Place, 15, 147-159.

Zakaria Mohd Yusof. (2005). Ke arah pengurangan kebergantungan tenaga kerja asing di sektor binaan. Jurnal Alam Bina, 7(2), 71-86.

Zulkifly Osman. (1998). Pekerja asing: dasar, teori dan amalan. In Abdul Ghafar Ismail \& Md. Zyadi Md. Tahir (Eds.). Makro ekonomi Malaysia: Perspektif dasar. Bangi, Universiti Kebangsaan Malaysia. 